\title{
Online Survey of Patients with Breast Cancer on Complementary and Alternative Medicine
}

\author{
Jutta Huebner ${ }^{\mathrm{a}}$ Karsten Muenstedt ${ }^{\mathrm{b}} \quad$ Franz J. Prott ${ }^{\mathrm{c}} \quad$ Christoph Stolle $^{\mathrm{O}}$ Oliver Micke \\ Jens Buentzelg $^{g}$ Ralph Muecke ${ }^{\text {h }}$ Bianca Senfd, on behalf of PRIO (Working group \\ Prevention and Integrative Oncology - German Cancer Society) \\ aWorking Group Integrative Oncology, Dr. Senckenberg Chronomedical Institute, J. W. Goethe University, Frankfurt/M., \\ ${ }^{b}$ Department of Gynecology and Obstetrics, University Clinic Gießen, \\ 'Radiooncology, RNS Praxisgemeinschaft GbR; Wiesbaden, \\ dDepartment for Psycho-Oncology, Clinic of the J.W. Goethe University, Frankfurt/M., \\ ${ }^{e}$ Clinic Herzoghöhe, Bayreuth, \\ fDepartment of Radiooncology, Franziskus Hospital, Bielefeld, \\ ${ }^{9}$ Clinic for Head and Neck Diseases, Nordhausen, \\ 'Department of Radiotherapy, Lippe Hospital, Lemgo/Department of Radiotherapy and Radiation Oncology, Ruhr University Bochum, \\ Germany
}

\section{Keywords}

Complementary and alternative medicine .

Patient information - Patient needs · Patient-physician communication · Interaction

\section{Summary}

About $50 \%$ of cancer patients use complementary and alternative medicine (CAM). Women with breast cancer use CAM more frequently than others. We linked a questionnaire to the largest internet portal for cancer patients in Germany. The questionnaire addresses attitude towards CAM, disclosure to the oncologist, source of information, and objectives for use of CAM. 80 patients with breast cancer took part in our study, 61 currently using CAM. Most frequently used CAM methods were selenium, relaxation techniques, prayer, vitamin $\mathrm{C}$, and meditation. Satisfaction was highest with relaxation techniques, vitamin C, homeopathy, yoga and Chinese herbs, lowest with mistletoe and acupuncture. $70 \%$ of participants did not think their oncologist took time to discuss CAM. Only $16 \%$ believed that their oncologist was wellinformed about CAM. 46\% relied on naturopaths and non-medical practitioners concerning CAM. Objectives for the use of CAM were to reduce side effects, boost the immune system, and become active.

\section{Introduction}

Patients with cancer often use complementary and alternative medicine (CAM). Surveys carried out in the last years provide data that about $40-50 \%$ of cancer patients use CAM [1]. Women with breast cancer use CAM much more frequently than patients with other cancers [2]. In a recent study from Germany, $90 \%$ of breast cancer patients disclosed using CAM [3]. In this study, vitamins, trace elements, and mistletoe were the most commonly used CAM. According to a European study, phytotherapy is also frequently used [4]. Family and friends and mass media are the most frequently chosen source of information, physicians are rarely involved [5]. In recent years, the internet has become more and more relevant to patients as a source of information in healthcare. Information about CAM on the internet is heterogeneous regarding content as well as quality [6-8]. From cancer patients' point of view, important characteristics of websites are reliability of sources (expert status and backup by well-known institutions) and easy access. Patients' insights and recommendations are highly valued by other patients as a source of information [9].

The internet is easily accessible at any time and at no substantial cost. An increasing number of chronically ill people use the internet to share their problems with other patients and to seek information. Unlike self-help groups, these platforms offer the possibility to exchange information anonymously and without physical effort. Patients have the opportunity to find others with similar diagnoses and issues. The anonymity of the internet is comfortable for some patients.

\section{KARGER \\ Fax +497614520714 \\ Information@Karger.com}

www.karger.com
(C) 2014 S. Karger GmbH, Freiburg

$1661-3791 / 14 / 0091-0060 \$ 39.50 / 0$

Accessible online at:

www.karger.com/brc
Dr. med. Jutta Hübner

Working Group Integrative Oncology

Dr. Senckenberg Chronomedical Institute

J. W. Goethe University

Theodor-Stern-Kai 7, 60590 Frankfurt am Main, Germany

Huebner@med.uni-frankfurt.de 
The largest German platform for cancer patients is 'Krebskompass' ('cancer compass'; www. krebskompass.de), which is supported by the non-profit Volker Karl Oehlrich Society. Krebskompass provides subforums for a variety of cancerrelated topics. Users have to register with the forum, and discussions are monitored by moderators who answer users' concerns about the forum and general questions, as well as respond to specific complaints. Advertising is prohibited, and product placement will lead to the exclusion of the author. As an independent patient platform uninfluenced by cancer societies or other institutions, Krebskompass offers excellent insight into patients' attitudes towards a large variety of topics - at least in relation to those patients likely to use the internet and forums. The purpose of this article is to depict the attitude of breast cancer patients using the internet as a source of information and for communication with fellow sufferers regarding CAM, their usage behavior, and their experiences with CAM.

\section{Material and Methods}

New discussion threads are commonly opened by new members of Krebskompass. The resulting discussions are mainly dominated by a small number of committed long-term members. Hence, for our project we decided to post a standardized online questionnaire on the Krebskompass website. This questionnaire was derived from a precursor which had been developed by experts of the working group 'Complementary Oncology' (Arbeitskreis Komplementäre Medizin in der Onkologie) of the German Cancer Society. This questionnaire was tested in a pilot study with cancer patients, and is currently being used in several ongoing oncological projects. The questionnaire starts with an open question in which we ask the patients to describe their attitude towards CAM in oncology, followed by several disease-related questions. Patients will then be asked whether they use CAM, and if so, whether they communicated this to their oncologist and what reaction they received. The core of the questionnaire con-

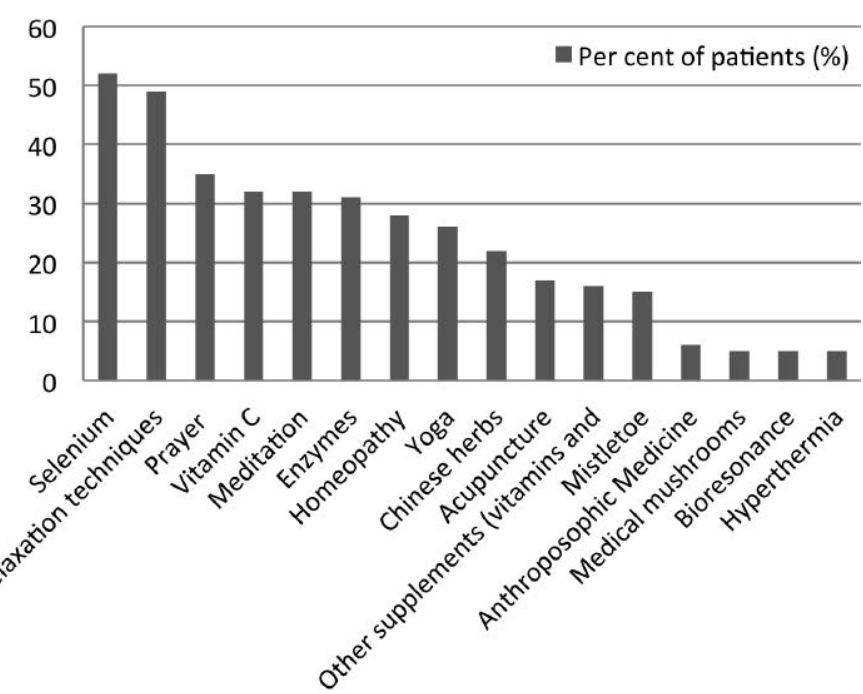

Fig. 1. Type of CAM method used by the patients (multiple responses were possible, hence the sum is in more than $100 \%$ ). sists of a table of the most commonly used CAM methods in Germany. Patients are asked to indicate whether they used this method prior to their illness and/or currently, and how satisfied they are with the method. Next, patients are asked for their aims using CAM. In the last section, patients are asked for symptoms such as pain, sleeplessness, fear, depression, fatigue, and distress, and their compliance with conventional medicine. Last, patients are asked for their subjective theory of illness, i.e. the assumed cause of their cancer. Our objective was to explore the correlation between CAM usage and burden of disease, as well as lay persons' subjective theories of illness and utilization of CAM. An online questionnaire was programmed using 'Access', and a link was published on the homepage of $w w w . k r e b s k o m p a s s . d e$ from 1st June 2011 to 31st October 2011. Statistics were done using IBM SPSS Statistics 20 (IBM Corp., Armonk, NY, USA).

\section{Results}

A total of 80 patients with breast cancer answered the questions. Of these, 67 currently received 1 or more types of conventional cancer therapies, 11 currently received no conventional treatment. 21 had metastases, 59 did not. 15 patients currently received chemotherapy ( 3 in combination with antibody therapy), 3 radiotherapy ( 2 in combination with chemotherapy), 34 endocrine therapy ( 2 in combination with antibody therapy and 2 in combination with bisphosphonates), and 2 were treated with bisphosphonates. 13 patients marked at least 2 kinds of therapy (chemo- and/or radiotherapy and/ or endocrine); consequently, we do not know their treatment stage at the time of the survey. 2 patients did not answer the item.

A total of 61 patients currently used CAM, 19 did not. Among the CAM users, 69\% (42/61) had talked about CAM with their oncologist, 31\% (19/61) had not. 62\% (38/61) had informed their general practitioner, 38\% (23/61) had not, and $56 \%(34 / 61)$ had informed another specialist. 39\% (24/61) of

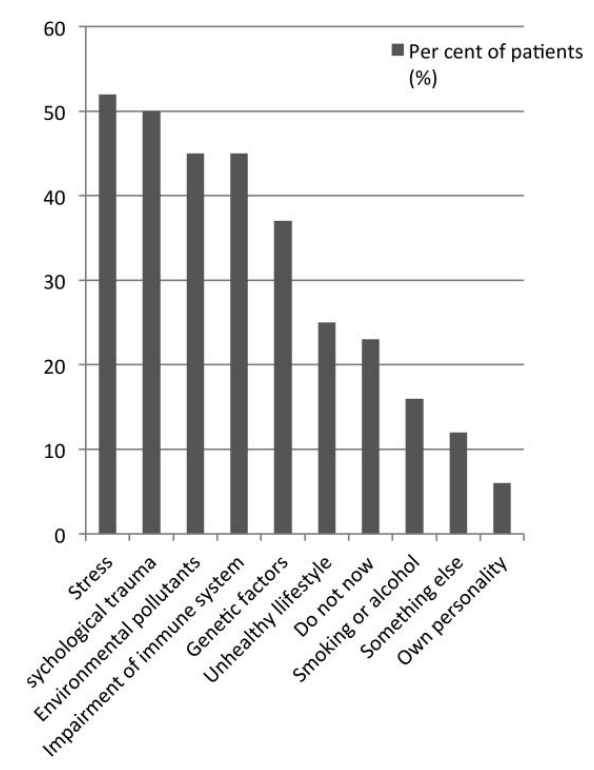

Fig. 2. Causes patients attributed their cancer to (multiple responses were possible; hence the sum is in more than $100 \%$ ). 
patients had informed their oncologist as well as their general practitioner, and 16 had fully disclosed their usage of CAM to all of their physicians.

Figure 1 shows which CAM methods the patients were currently using. There was no significant difference concerning CAM usage between patients currently being treated conventionally or not. Also, having metastasis had no influence in our sample. Psychological symptoms, such as anxiety, depression, fatigue, sleep disorders and pain, self-rated by the patients, were uncorrelated with CAM usage. Compliance with conventional medicine (self-rated) and CAM usage was also unrelated.

Several questions addressed the communication between physicians and patients regarding CAM. 53\% (42/80) of patients had a physician whom they believe to be well-informed on CAM. In $12 \%$, this was the oncologist, in $14 \%$ another specialist, and in $20 \%$ the general practitioner. $19 \%$ of patients had a naturopath, and $16 \%$ consulted a non-medical practitioner. $18 \%$ of patients marked 'somebody else' and $14 \%$ 'none at all'. 4 patients did not answer this question. 30\% of patients indicated that their oncologist took sufficient time to discuss CAM, 70\% do not think so. To the question who explained how CAM works, $33 \%$ of patients answered their oncologist, $28 \%$ their general practitioner, and 39\% their non-medical practitioner. $80 \%$ of patients claimed, they understood how CAM works and $20 \%$ did not.

Patients who rated the non-medical practitioner higher than the other professions most often used CAM (91\%; 29/32). Patients who declared they understood how CAM works, used CAM more often $(81 \% ; 52 / 64)$ than those who said they did not understand it $(56 \% ; 9 / 16)$. Accordingly, patients indicating that they knew a person who is competent in CAM used CAM more frequently $(90 \% ; 38 / 42)$ than people who relied on other sources of information $(62 \%$; 23/37). In contrast, there was no influence of the oncologist having time to discuss CAM.

Most patients named stress and psychological trauma as assumed causes for their cancer. The next most frequent responses are 'environmental pollutants' and 'impairment of immune system'. The whole list is given in figure 2. All assumed causes for cancer correlated positively with CAM usage, except for alcohol and/or smoking. Patients, who assumed alcohol and/or smoking to be a cause of their cancer, did not use CAM more often than patients who did not. CAM may be used for different purposes. The objectives patients named for using CAM are shown in figure 3.

In the next step, we analyzed if using any of the most often named CAM methods is correlated with specific objectives. In table 1 , the most important reasons and CAM methods or substances are listed. Significant correlations are summarized in table 2.

Finally, we analyzed whether patients were satisfied with the methods they used. The original scale with ratings from very satisfied $(=1)$ to not at all satisfied $(=6)$ was transformed into a scale with 3 categories: satisfied, neither satisfied nor not satisfied, and not satisfied. The results are shown in figure 4. In this diagram, all methods show a satisfaction level of more than $50 \%$, yet there are several differences. Satisfaction is highest $(>70 \%)$ with patients who use relaxation techniques $(71 \%)$, vitamin C (73\%), homeopathy $(75 \%)$,

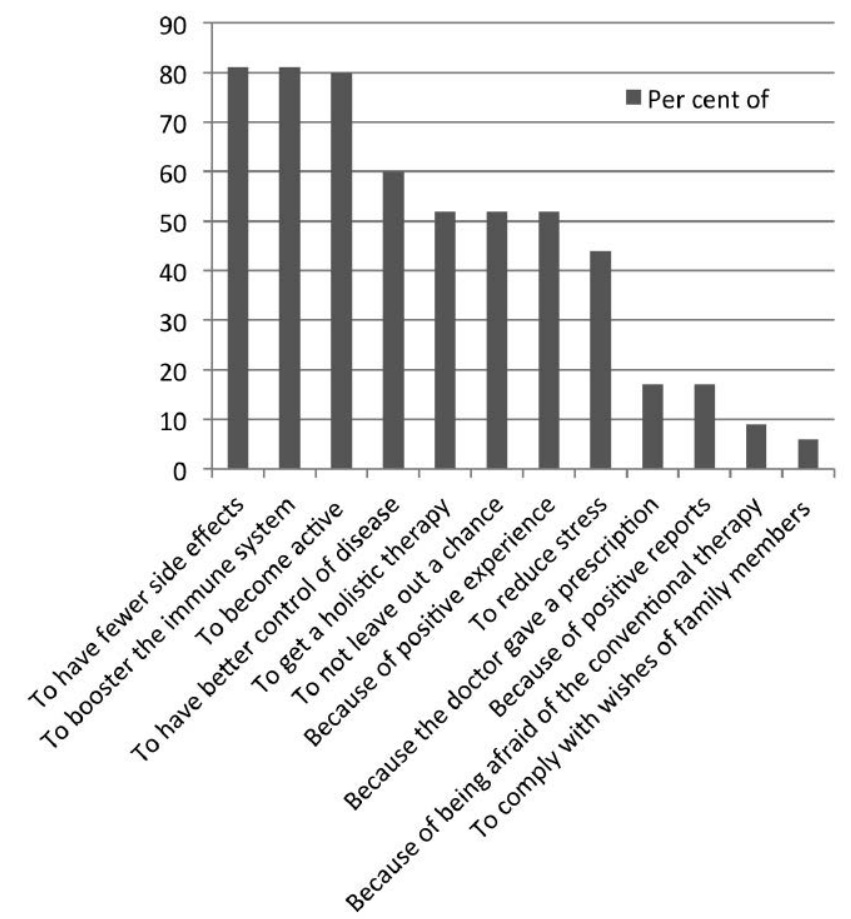

Fig. 3. Patients' objectives for using CAM (multiple responses were possible, hence the sum is in more than $100 \%$ ).

Table 1. CAM methods used by the patients, and objectives for CAM use

\begin{tabular}{|c|c|c|c|c|c|c|c|c|c|c|c|c|}
\hline \multirow[t]{2}{*}{ Objective } & \multicolumn{12}{|c|}{ CAM method } \\
\hline & selenium & $\begin{array}{l}\text { relaxation } \\
\text { techniques }\end{array}$ & prayer & vitamin $\mathrm{C}$ & meditation & enzymes & $\begin{array}{l}\text { homeo- } \\
\text { pathy }\end{array}$ & yoga & $\begin{array}{l}\text { Chinese } \\
\text { herbs }\end{array}$ & $\begin{array}{l}\text { acupunc- } \\
\text { ture }\end{array}$ & $\begin{array}{l}\text { other } \\
\text { supplements }\end{array}$ & mistletoe \\
\hline $\begin{array}{l}\text { To have less side } \\
\text { effects }\end{array}$ & n.s. & n.s. & 0.009 & 0.029 & n.s. & 0.039 & 0.011 & n.s. & 0.028 & n.s. & 0.013 & 0.029 \\
\hline $\begin{array}{l}\text { To booster the } \\
\text { immune system }\end{array}$ & 0.009 & 0.029 & 0.032 & 0.044 & 0.003 & 0.049 & n.s. & n.s. & n.s. & n.s. & 0.045 & 0.041 \\
\hline To become active & n.s. & 0.04 & n.s. & n.s. & 0.005 & 0.041 & 0.029 & n.s. & 0.037 & n.s. & n.s. & n.s. \\
\hline
\end{tabular}

n.s. $=$ Not significant. 


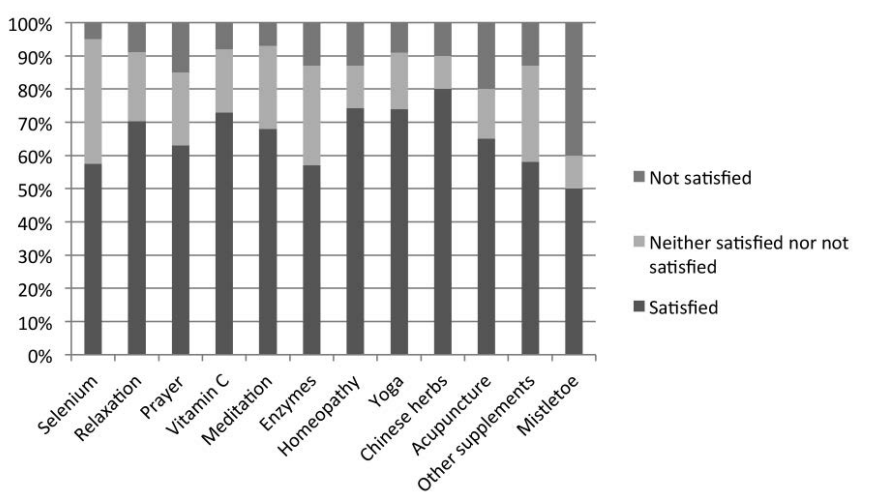

yoga $(74 \%)$, and Chinese herbs $(80 \%)$. Satisfaction is lowest with mistletoe therapy. Patients also report highest dissatisfaction with mistletoe therapy $(45 \%)$, followed by acupuncture $(20 \%)$.

\section{Disclosure Statement}

The authors declare no conflict of interest.

Fig. 4. Satisfaction of patients with the different methods.

Table 2. Most important reasons for use of CAM, and methods used

\begin{tabular}{lll}
\hline Reason for CAM use & Positively correlated method & Not correlated method \\
\hline To have less side effects & $\begin{array}{l}\text { prayer, vitamin C, other supplements, enzymes, } \\
\text { homeopathy, Chinese herbs, mistletoe } \\
\text { Tistletoe, selenium, other supplements, vitamin C, } \\
\text { To booster the immune system } \\
\text { To become active }\end{array}$ & $\begin{array}{l}\text { selenium, relaxation techniques, meditation, yoga, } \\
\text { acupuncture } \\
\text { homeopathy, yoga, Chinese herbs, acupuncture } \\
\text { homeopathy, Chinese herbs }\end{array}$ \\
\hline
\end{tabular}

\section{References}

1 Horneber M, Bueschel G, Dennert G, Less D, Ritter E, Zwahlen M: How many cancer patients use complementary and alternative medicine: a systematic review and metaanalysis. Integr Cancer Ther 2012;11:187-203.

2 Büntzel J, Glatzel M, Bruns F, Kisters K: Use of complementary/alternative therapy methods by patients with breast cancer. Forsch Komplementarmed Klass Naturheilkd 2003;10:304-8.

3 Micke O, Bruns F, Glatzel M, Schönekaes K, Micke P, Mücke R, Büntzel J: Predictive factors for the use of complementary and alternative medicine (CAM) in radiation oncology. Eur J Integr Med 2009;1:22-30.
4 Molassiotis A, Fernadez-Ortega P, Pud D, Ozden G, Scott JA, Panteli V, Margulies A, Browall M, Magri M, Selvekerova S, Madsen E, Milovics L, Bruyns I, Gudmundsdottir G, Hummerston S, Ahmad AM, Platin N, Kearney N, Patiraki E: Use of complementary and alternative medicine in cancer patients: a European survey. Ann Oncol 2005;16:655-63.

5 Eschiti VS: Lesson from comparison of CAM use by women with female-specific cancers to others: it's time to focus on interaction risks with CAM therapies. Integr Cancer Ther 2007;6:31344.
6 Schmid K, Ernst E: Assessing websites on complementary and alternative medicine for cancer. Ann Oncol 2004;15:733-42.

7 Matthews SC, Camacho A, Mills PJ, Dimsdale JE: The internet for medical information about cancer: help or hindrance? Psychosomatics 2003;44:100-3.

8 Brauer JA, El Sehamy A, Metz JM, Mao JJ: Complementary and alternative medicine and supportive care at leading cancer centers: a systematic analysis of websites. J Altern Complement Med 2010;16:183-6.

9 Maddock C, Camporesi S, Lewis I, Ahmad K, Sullivan R: Online information as a decision making aid for cancer patients: recommendations from the Eurocancercoms project. Eur J Cancer 2012;48: 1055-9. 